\title{
Age Does Not Affect Numbers of Taste Buds and Papillae in Adult Rhesus Monkeys
}

\author{
ROBERT M. BRADLEY, HAZEL M. STEDMAN, AND CHARLOTTE M. MISTRETTA \\ Department of Oral Biology, School of Dentistry, \\ University of Michigan, Ann Arbor, MI 48109
}

\begin{abstract}
Taste buds and papillae in tongues of rhesus monkeys were examined and counted to determine if there are age-related differences in general morphology or numbers of receptor organs. Tongues from 15 monkeys in five groups aged 4-31 years were studied with light microscopy. Fungiform, circumvallate, and foliate papillae were examined and taste buds in each papilla type were counted. Numbers of papillae did not differ with age through 31 years; however, at 24 years and older, fungiform papillae were reduced in number in some animals that had lost tongue tips due to trauma. There were no age-related differences in numbers of taste buds in any of the three gustatory papilla types, nor did taste bud diameter alter with age. From data on each papilla type, estimates were made of total numbers of lingual taste buds. Totals ranged from about 8,000 to 10,000 and there were no agerelated differences. These results support other recent reports that taste buds are not decreased in number in old rats or humans. Since taste bud numbers and general morphology are maintained even in old age, any age-related differences in taste behavior cannot be attributed to gross degenerative changes in lingual taste buds.
\end{abstract}

There are few studies of age-related differences in taste bud numbers and existing observations are contradictory. In the early literature loss of taste buds in circumvallate papillae from aged human and mouse tongues was reported (Arey et al., 1935; Conger and Wells, 1969; Mochizuki, 1937). More recently investigators have found no age-related differences in taste bud numbers in fungiform papillae of humans (Arvidson, 1979) or rats (Mistretta and Baum, 1984). From a general review of this literature, it is difficult to know to what extent varying conclusions relate to differences in methods, species, or in types of taste papillae that were examined. The latter possibility is not trivial since taste papillae have very different morphology, numbers of taste buds, and innervation. Therefore we have examined taste buds in fungiform, circumvallate, and foliate papillae from a single species, the rhesus monkey, to learn whether taste bud number is reduced in old age.

The tongue of the rhesus monkey is spatulate and covered with numerous filiform papillae (Bradley, 1971; Schneider, 1958; Sonntag, 1921). Interspersed among the filiform papillae on the anterior two-thirds of the tongue are fungiform papillae, which are especially numerous at the tip. On the back of the tongue there are usually four circumvallate papillae arranged in a V-shape with the apex of the $\mathrm{V}$ directed posteriorly. At the apex of the $\mathrm{V}$ is a posterior group of one to three circumvallate papillae, and there is one papilla at the end of each leg of the V. On each side of the posterior lateral border of the tongue is a single foliate papilla, composed of several clefts.

The number of lingual taste buds in monkeys has been quantified in a few studies. Fungiform papillae in the cynomolgus Old World monkey reportedly contain from zero to 36 taste buds (Arvidson et al., 1981; Brouwer and Wiersma, 1978), and the circumvallate papillae contain an average of 521 taste buds each (Brouwer and Wiersma, 1978). There are no reports of the total number of taste buds in the monkey foliate papilla, but Brouwer and Wiersma (1978) observed that one wall of a cleft contains an average of 183 taste buds.

In past studies, monkeys have been identified as adults but age of animals has not been provided. The availability of tongue specimens from a group of rhesus monkeys of known age (Davis and Leathers, 1985) has made possible a quantitative study of taste buds in each type of gustatory papilla from 4 to 31 years. Since the maximum life span of a macaque is reported to be 30 years (Altman and Dittmer, 1972), this range extends into extreme old age.

\section{MATERIALS AND METHODS}

Tongues were obtained from 15 rhesus monkeys, aged $4,8,13,24$, and 31 years (three per age group), from the Aging Monkey Tissue Organ Resource Study of Washington State University. The tongues were excised and fixed by immersion in formalin at death. They were photographed and inspected for gross lesions or abnormalities. By coating the tongue with a water-soluble dye all gustatory papillae were easily visualized and counted under a dissecting microscope. Subsequently, taste buds in each type of papilla were examined and quantified.

\section{Fungiform Papillae}

Taste pores in fungiform papillae in the intact tongue were stained with 5\% Ponceau S red in $10 \%$ trichloroa-

Received December 6, 1984; accepted January 31, 1985. 
cetic acid (Brouwer and Wiersma, 1978). The stained taste pores were counted under a dissecting microscope and a map was made of the number of pores in the fungiform papillae on the left half of each tongue. Subsequently, these counts were verified by counting the number of taste buds in histological sections of ten fungiform papillae from each tongue. The papillae were sectioned perpendicular to the dorsal tongue surface at $15 \mu \mathrm{m}$ and stained with hematoxylin and eosin. Histological counts of the taste buds were within $10 \%$ of the counts in intact tongues. Using a calibrated reticule, diameters of 20 taste buds per tongue were measured in histological sections that contained the taste pore.

\section{Circum: 'allate and Foliate Papillae}

The most posterior group of circumvallate papillae was dissected from the tongue, embedded in paraffin, sectioned parallel to the tongue surface at $20 \mu \mathrm{m}$, and stained with hematoxylin and eosin. The entire foliate papilla was excised from the left side of each tongue, sectioned at $20 \mu \mathrm{m}$, and stained with hematoxylin and eosin. The diameter of 20 taste buds from both the circumvallate and foliate papillae of each animal was measured with a calibrated reticule positioned over a taste bud section containing the pore.

The number of taste buds per papilla was then determined by counting the occurrence of all taste bud sections, multiplying by the thickness of the sections (20 $\mu \mathrm{m}$ ), and dividing by taste bud diameter (Arey et al., 1935; Bradley et al., 1980).

\section{Data Analysis}

Tongues were coded so that age of each specimen was concealed until papilla and taste bud quantification were completed. Numbers of various papilla types and taste buds were compared across age groups with analysis of variance. A significance level of $P \leqslant .05$ was used.

\section{RESULTS}

\section{Surface Examination}

Tongues of monkeys from the three youngest age groups were similar to each other and appeared normal in general topography. In contrast, two of the three monkeys aged 24 years and all three animals aged 31 years had scarred or atrophied tongue tips. In one 31year-old monkey the entire tongue tip was absent anterior to the lingual frenum. The cause of this trauma is unknown but may be due to the fact that the monkeys were allowed outside in subzero weather and could have licked metal surfaces, thereby causing frost damage to the anterior tongue. Alternatively, since they were socially housed in pairs, they could have bitten the tips of their cage-mate's tongue (Davis, personal communication).

\section{Fungiform Papillae}

The average number of fungiform papillae per tongue differed as a function of age $(\mathrm{F}=5.95$, $\mathrm{df}=4,14, P<$ .05). Post-tests demonstrated that numbers remained constant through 13 years and then decreased in 24 - and 31-year monkeys. However, the apparent decrease with age was due to loss of anterior tongue tissue, not to loss of papillae per se. In fact the one intact tongue in the 24-year age group had a total number of papilla equal to or greater than that in several of the younger tongues.

At all ages, taste buds were maintained in the fungiform papillae (Fig. 1). The average number of taste buds per papilla was four to five across ages, and the range was 0 to 31 . There was no difference in mean number of taste buds per papilla in the five age groups $(F=1.86$, $\mathrm{df}=4,14, P>.05$ ). Nor was there a difference in taste bud diameter $(F=1.27$, $\mathrm{df}=4,14 P>.05)$, which averaged $50 \mu \mathrm{m}$ across groups. The percentage of papillae that contained no taste buds was $10,9,9,22$, and 15 for the five age groups, respectively; these differences were not statistically significant $(\mathrm{F}=2.77 \mathrm{df}=4,14, P$ $>$.05). Thus, not only were average numbers of taste buds per papilla constant, but also there was no increase in number of papillae without taste buds in the older animals.

\section{Circumvallate Papillae}

The number of circumvallate papillae varied from four to six per tongue. There were usually two anterior papillae, but the number of posterior papillae ranged from one to three and two occurred most frequently ( $73 \%$ of tongues). Numbers of taste buds per circumvallate papilla were quite variable (Fig. 1) and variances across groups were not equal $(P<.05)$. Therefore we used the Kruskal-Wallis statistic to test for an age-related difference and found no change $(P>.05)$. Nor were there differences in the number of taste buds per total posterior group of papillae as a function of age $(\mathrm{F}=1.59$, $\mathrm{df}$ $=4,14, P>.05)$. Diameters of taste buds remained zonstant at all ages ( $\mathrm{F}=0.66 \mathrm{df}=4,14, P>.05)$, and ihe average diameter across groups was $48 \mu \mathrm{m}$.

\section{Foliate Papillae}

The total number of taste buds per foliate papilla was not different across age groups $(F=0.94$, $\mathrm{df}=4,14, P$ $>.05)$ nor was the diameter of taste buds $(F=1.09$, df $=4,14, P>.05)$. Taste bud diameter averaged $49 \mu \mathrm{m}$ across age groups.

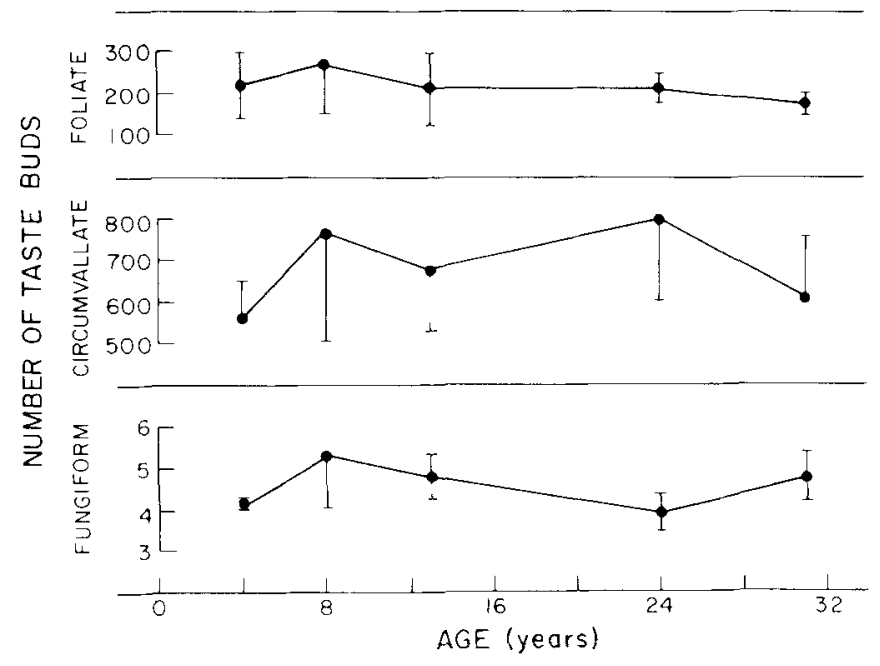

Fig. 1. Mean number of taste buds in the fungiform and circumvallate papillae and foliate papilla clefts of rhesus monkey tongues as a function of age. Bars represent standard deviations. 
TABLE 1. Estimated total number of lingual taste buds and percentage of taste buds in each papilla type

\begin{tabular}{rrccc}
\hline Age (years) & $\begin{array}{c}\text { Total } \\
\text { (mean and S.D.) }\end{array}$ & $\begin{array}{c}\text { Percentage } \\
\text { fungiform }\end{array}$ & $\begin{array}{c}\text { Percentage } \\
\text { circumvallate }\end{array}$ & $\begin{array}{c}\text { Percentage } \\
\text { foliate }\end{array}$ \\
\hline 4 & $8,044 \pm 1,844$ & 16 & 27 & 57 \\
8 & $10,650 \pm 1,620$ & 16 & 32 & 52 \\
13 & $8,053 \pm 1,570$ & 22 & 34 & 44 \\
24 & $8,623 \pm 2,473$ & 11 & 42 & 47 \\
31 & $7,044 \pm 1,533$ & 12 & 38 & 50 \\
\hline
\end{tabular}

\section{Total Number of Lingual Taste Buds}

Using the observed average number of taste buds per papilla type and adjusting papilla numbers to totals for an entire tongue, an estimate of the total number of lingual taste buds for each age group was derived (Table 1). There was no difference in number of taste buds as a function of age $(\mathrm{F}=1.58, \mathrm{df}=4,14, P>.05)$. In addition, the percentage of taste buds in each papilla type relative to total taste buds (Table 1 ) did not differ significantly with age (fungiform: $\mathrm{F}=2.68, \mathrm{df}=4,14, P>$ .05 ; circumvallate: $\mathrm{F}=1.38, \mathrm{df}=4,14, P>.05$; foliate: $\mathrm{F}=0.73, \mathrm{df}=4,14, P>.05$ ). Even though there was a loss of anterior tongue tissue due to trauma and there fore of fungiform papillae in the oldest animals, the loss was not sufficient to result in a significant decrease in percentage of fungiform papilla taste buds.

\section{DISCUSSION}

In rhesus monkeys aged 4 to 31 years there are no significant differences in numbers of taste buds per fungiform, circumvallate, or foliate papilla, or in diameter of taste buds as a function of age. Thus there are large numbers of taste buds in all three gustatory papilla types even in the oldest monkeys.

This conclusion contrasts with the frequent assertion that taste bud numbers decrease with age (Hiji, 1976; Kamath, 1982). The origin of this statement derives from investigations of taste bud numbers in human circumvallate and foliate papillae conducted over 40 years ago (Arey et al., 1935; Mochizuki, 1937, 1939a,b). The tissue used in these studies was from cadavers with no information on the cause of death and only tissue that was "highly pathological" was excluded from examination. In addition, even though taste bud numbers were reportedly decreased by $50 \%$ in circumvallate papillae in old age (Arey et al., 1935; Mochizuki, 1937), no statistics were used so it is not certain that the decrease was statistically significant. This problem is apparent in the study of human foliate papillae by Mochizuki (1939b) in which he reported 108 taste buds per cleft in juveniles (birth to 20 years), 136 in mature individuals (21-60 years), and 109 in old age (61-90 years). He concluded from these data that there was a decrease in foliate taste bud numbers in old age. However, between the juvenile and old-age specimens there is no difference in numbers and it is doubtful if the difference between maturity and old age is statistically significant.

Even in later studies reporting a decline in taste bud numbers there were problems in data analysis. For example, Conger and Wells (1969) reported a $30 \%$ decrease in taste buds in the circumvallate papilla of mice from 6 to 27 months. However, a relatively small number of tissue sections was sampled from each papilla and number of taste buds was then extrapolated to the entire papilla. In addition, no statistical tests were performed to indicate if the observed differences were significant.

Recent studies report no significant difference in taste bud numbers with aging. Arvidson (1979) studied fungiform papillae in human tongues at autopsy from individ. uals aged 2 days to 90 years; autopsies were performed 5-12 hours after death due to traffic accident or sudden cardiac infarction. There was no age-related difference in average number of taste buds per papilla. Mistretta and Baum (1984) examined fungiform and circumvallate papillae in Wistar rats aged 6 and 24 months and found no significant differences in numbers of taste buds in either papilla type. These investigations complement data from the present study and demonstrate that there are no significant differences in number of taste buds in aged mammals when appropriate measurements and data analysis are used on healthy tongues.

Although number of fungiform papillae was reduced in monkeys aged 24 and 31 years due to trauma of the tongue tip, the reduction was not sufficient to effect a significant decrease in percentage of fungiform papilla taste buds relative to the total number of lingual taste buds. Taste buds in fungiform papillae are always a low percentage of total lingual taste buds in mammals (Table 2). The percentage in monkeys may be even lower than reported here because the estimate is based on average taste bud number per papilla and does not take into account that a mean of $13 \%$ of monkey fungiform papillae have no taste buds. This is perhaps a characteristic of primates since Arvidson et al. (1981) reported that $14 \%$ of fungiform papillae in cynomolgus monkeys

TABLE 2. Taste bud counts in each papilla type in various mammals and percentage of total tongue taste buds

\begin{tabular}{|c|c|c|c|c|c|c|c|}
\hline \multirow[b]{2}{*}{ Animal } & \multicolumn{2}{|c|}{ Fungiform } & \multicolumn{2}{|c|}{ Circumvallate } & \multicolumn{2}{|c|}{ Foliate } & \multirow[b]{2}{*}{$\begin{array}{l}\text { Lingual } \\
\mathrm{N} \text { total }\end{array}$} \\
\hline & $\mathrm{N}$ & $\begin{array}{c}\% \\
\text { total }\end{array}$ & $\mathbf{N}$ & $\begin{array}{c}\% \\
\text { total }\end{array}$ & $\mathrm{N}$ & $\begin{array}{c}\% \\
\text { total }\end{array}$ & \\
\hline Rat $^{1}$ & 185 & 19 & 350 & 35 & 460 & 46 & 995 \\
\hline Hamster $^{2}$ & 130 & 25 & 168 & 32 & 230 & 44 & 528 \\
\hline Cow $^{3}$ & 1,707 & 9 & 16,519 & 91 & - & - & 18,226 \\
\hline Monkey ${ }^{4}$ & 1,296 & 16 & 2,896 & 35 & 4,294 & 50 & 8,485 \\
\hline
\end{tabular}

${ }^{\text {I}}$ Miller (1977).

2 Miller and Smith (1984).

${ }^{3}$ Davies et al. (1979).

${ }^{4}$ Present study. 
are without taste buds. In humans about $60 \%$ of fungiform papillae contain no taste buds (Arvidson, 1979).

While there are species differences in distribution of taste buds on the tongue, it is apparent that the majority of buds are in posterior tongue papillae. It is interesting that most studies of taste bud physiology are on fungiform taste buds; if numbers are of any significance in indicating function, the posterior taste buds are perhaps more important.

Based on the finding that there are similar numbers of taste buds in young and old monkeys and on the intact morphology of the taste buds and gustatory papillae in old monkeys, the peripheral taste system seems to be little affected by the aging process. Although taste buds in old animals might differ at the ultrastructural or biochemical level, any age-related difference in taste behavior is unlikely to be caused by gross degenerative changes in the lingual taste buds.

\section{ACKNOWLEDGMENTS}

This work was supported in part by N.S.F. grant BNS 83-11497 and N.I.H. grant DE05782.

\section{LITERATURE CITED}

Altman, P.L., and D.S. Dittmer (1972) Biology data book. Fed. Am. Soc. Exp. Biol., 1:230.

Arey, L.B., M.J. Tremaine, and F.L. Monzingo (1935) The numerical and topographical relations of taste buds to human circumvallate papillae throughout the life span. Anat. Rec. 64:9-25.

Arvidson, K. (1979) Location and variation in number of taste buds in human fungiform papillae. Scand. J. Dental Res., 87:435-442.

Arvidson, K., M. Cottler-Fox, and V. Friberg (1981) Taste buds of the fungiform papillae in Cynomologus monkey. J. Anat., 133:271-280.

Bradley, R.M. (1971) Tongue topography. In: Handbook of Sensory
Physiology. Vol. IV. Part 2. L.M. Beidler, ed. Springer-Verlag, Berlin, pp. 1-30.

Bradley, R.M., M.L. Cheal, and Y.H. Kim (1980) Quantitative analysis of developing epiglottal taste buds in sheep. J. Anat., 130:25-32

Brouwer, J.N and A. Wiersma (1978) Location of taste buds in intact taste papillae by a selective staining method. Histochem., 58:145151.

Conger, A.D., and M.A. Wells (1969) Radiation and aging effect on taste structure and function. Radiat. Res., 37:31-49.

Davies, R.O., M.R. Kare, and R.H. Cagan (1979) Distribution of taste buds on fungiform and circumvallate papillae of bovine tongue. Anat. Rec., 195:443-446.

Davis, R.T., and C.W. Leathers (1985) Behavior and Pathology of Aging in Rhesus Monkeys. Alan R. Liss, Inc., New York, (in press).

Hiji, Y. (1976) Alterations of taste acuity as a function of age in man. IRCS Med. Sci., 4:570.

Kamath, S.K. (1982) Taste acuity and aging. Am. J. Clin. Nutr., 36:766775

Miller, I.J. (1977) Gustatory receptors of the palate. In: Food Intake and the Chemical Senses. Y. Katsuki, M. Sato, S.F. Takagi, and Y. Oomura, eds. Japan Scientific Societies Press, Japan, pp. 173-185.

Miller, I.J., and D.V. Smith (1984) Quantitative taste bud distribution in the hamster. Physiol. Behav., 32:275-286.

Mistretta, C.M., and B.J. Baum (1984) Quantitative study of taste buds in fungiform and circumvallate papillae of young and aged rats. J. Anat., 138:323-332.

Mochizuki, Y. (1937) An observation on the numerical and topographical relations of taste buds to circumvallate papillae of Japanese. Okajimas Folia Anat. Jap., 15:595-608.

Mochizuki, Y. (1939a) Studies on the papilla foliata of Japanese 1. The number of papillae foliatae. Okajimas Folia Anat. Jpn., 18:337354.

Mochizuki, Y. (1939b) Studies on the papilla foliata of Japanese 2. The number of taste buds. Okajimas Folia Anat. Jpn., 18:355-369.

Schneider, R. (1958) Zunge und Weicher Gaumen. Primatologia, 3:61127.

Sonntag, C.F. (1921) The comparative anatomy of the tongues of the mammalia-III. Family 2. Cercopithecidae: with notes on the comparative physiology of the tongues and stomachs of the langurs. Proc. Zool. Soc. Lond., 277-322. 